\title{
Eficacia del proceso de limpieza y desinfección de los endoscopios en un hospital de nivel III
}

\author{
Efficacy of the cleaning and disinfection processes of endoscopes in a level III hospital \\ Luz María Samamé 1,a,b, Frine Samalvides ${ }^{2, c, d}$
}

\section{RESUMEN}

Objetivos: Determinar la eficacia del proceso de limpieza y desinfección de los endoscopios en un hospital de nivel III, y determinar los agentes patógenos más comunes encontrados antes y después del proceso. Material y métodos: Estudio descriptivo tipo serie de casos realizado en agosto, setiembre y octubre del 2010. Se evaluaron 50 ciclos de limpieza y desinfección de endoscopios. Para el aislamiento de microorganismos patógenos se utilizaron medios de cultivos y las pruebas de coagulasa, oxidasa y de pigmentos, medio Agar selectivo (Agar Verde Brillante, Agar Xilosa Lisina Desoxicolato, Agar con Sulfito de Bismuto), y medio Agar Mc Conkey. Resultados: La media del recuento de microorganismos antes del proceso de limpieza y desinfección de los endoscopios fue $835,3 \pm 1$ 114,6 UFC/ml, la mediana $233 \mathrm{UFC} / \mathrm{ml}$. Después del proceso la media fue 236,3 $\pm 700,7 \mathrm{UFC} / \mathrm{ml}$ y la mediana $10 \mathrm{UFC} / \mathrm{ml}$, esta diferencia fue estadísticamente significativa $(p=0,000001)$. La carga bacteriana antes del proceso fue positiva en $88 \%$ y después del proceso en $26 \%$. Se encontró diferencia estadísticamente significativa para Pseudomonas aeruginosa $(\mathrm{p}=0,006)$ y Salmonella enterica $(\mathrm{p}=0,00001)$. La carga bacteriana después del décimo día de activación del desinfectante fue positiva en 55\% y antes del noveno día, 19\%. Conclusiones: El proceso de limpieza y desinfección de los endoscopios no es efectivo. Los microorganismos patógenos más frecuentes fueron: Salmonella entérica, Pseudomonas aeruginosa y Escherichia coli. El desinfectante de alto nivel (glutaraldehído al $2 \%$ ) no es efectivo después del décimo día de haber sido activado.

PALABRAS CLAVE: Endoscopios gastrointestinales, infecciones bacterianas, desinfección, contaminación de equipos. (Fuente: DeCS BIREME).

\section{SUMMARY}

Objectives: To determine the efficacy of the cleaning and disinfection processes of endoscopes in a level III hospital, and to determine the most common pathogens found before and after these procedures. Methods: Case series from August to October 2010. A total of 50 cycles of cleaning-disinfection procedures were evaluated. Culture media (Brilliant blue agar, xylose-lisine-deoxycholate, sulfite bismute, Mc Conkey) as well as coagulase and oxidase tests were used. Results: The mean count of bacteria before the procedures was $835.3 \pm 1,114.6 \mathrm{UFC} / \mathrm{ml}$; the median count was $233 \mathrm{UFC} / \mathrm{ml}$; respective values after the procedures were $236.3 \pm 700.7 \mathrm{UFC} / \mathrm{ml}$ and $10 \mathrm{UFC} /$ $\mathrm{ml}$, respectively, a statistical difference was found $(\mathrm{p}=0.000001)$. Bacterial load was positive before the procedures in $88 \%$, and $26 \%$ after them. A statistical significant difference was found for Pseudomonas aeruginosa $(\mathrm{p}=0.006)$ and Salmonella entérica $(\mathrm{p}=0.00001)$. Bacterial load was positive in $55 \%$ after 10 days of using the disinfectant and it was 19\% after the ninth day. Conclusions: The cleaning-disinfection process is not effective. Salmonella

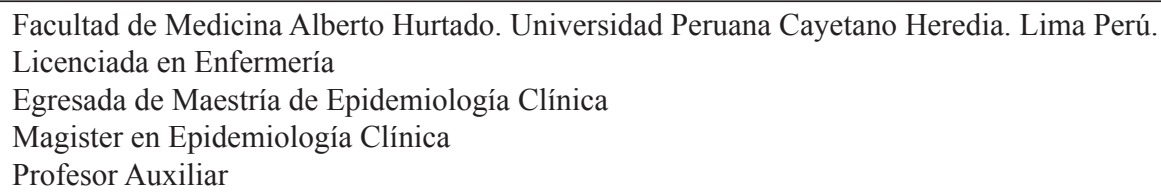


enterica, Pseudomonas aeruginosa and Escherichia coli were the most frequent isolated pathogens. The high level disinfectant ( $2 \%$ glutaraldehyde) is not effective after the tenth day.

KEYWORDS: Gastrointestinal endoscopes, bacterial infections, disinfection, contamination of equipment. (Source: MeSH NLM).

\section{INTRODUCCIÓN}

En Estados Unidos se realizan anualmente un promedio de 17000000 endoscopias (1). Considerando que en los países de América Latina se cuenta también con las últimas tecnologías en instrumentos que permiten realizar los procedimientos endoscópicos a pacientes pediátricos y adultos con fines de diagnóstico o tratamiento en enfermedades del aparato digestivo que antes requerían de cirugías complejas. Como consecuencia de ello se ha conseguido disminuir el índice de morbilidad, mortalidad y reducir la estancia hospitalaria; sin embargo este procedimiento puede exponer al paciente a adquirir una infección trasmitida por esta vía, siendo éste uno de los mayores retos que enfrentamos los profesionales de la especialidad.

Los equipos endoscópicos utilizados con fines diagnósticos o terapéuticos deben ser sometidos a métodos de limpieza y desinfección para evitar la infección por gérmenes intrahospitalarios. El riesgo de diseminación hematógena en una endoscopia varía entre $4 \%$ y $8 \%$; con un incremento hasta de $30 \%$ en esclerosis y dilataciones esofágicas. Asimismo los pacientes de cuidados críticos o inmunosuprimidos tienen mayor riesgo de adquirir infecciones asociadas a estos procedimientos (2).

El desinfectante recomendado y de uso institucional es el glutaraldehído al $2 \%$, el cual es eficaz durante 14 días pero se va diluyendo con el uso, por lo que debe supervisarse la concentración mínima eficaz (CME) (3).

Está demostrado que los endoscopios pueden facilitar la formación de biofilm (4) provocando la transmisión de agentes infecciosos. Diversos trabajos de investigación han demostrado la contaminación de los endoscopios luego de ser sometidos a un proceso de desinfección de alto nivel $(5,6,7)$.

En Lima - Perú, en un hospital nacional de nivel III, donde se realiza un promedio de 7200 endoscopias al año, hasta la fecha no se han realizado estudios relacionados al tema que nos permita conocer la eficacia del proceso de limpieza y desinfección de los endoscopios y la repercusión que este tendría en la atención de los pacientes.

El objetivo general del estudio fue determinar la eficacia del proceso de limpieza y desinfección de los endoscopios en un hospital de nivel III, determinando el recuento de carga bacteriana antes y después del proceso de la limpieza y desinfección, los agentes patógenos más comunes y el nivel de carga bacteriana según días de activación del desinfectante.

\section{MATERIAL Y MÉTODOS}

Estudio descriptivo tipo serie de casos, realizado en el servicio de hemorragia digestiva, Departamento de Gastroenterología de un hospital de nivel III de la ciudad de Lima entre agosto y octubre de 2010. Se evaluaron 50 ciclos de limpieza y desinfección de endoscopios. El servicio cuenta con 5 endoscopios, guías de procedimientos endoscópicos y del proceso de limpieza y desinfección. El proceso incluyó lavado manual con detergente enzimático, cepillado de canales, enjuague, secado, inmersión en glutaraldehído al $2 \%$, aclarado y secado. Considerándose a los equipos con los que se cumplieron todas las etapas del proceso para la toma de muestra.

Se consideró eficaz al proceso de limpieza y desinfección, cuando el cultivo fue negativo para diversos gérmenes comunes $(<20 \mathrm{UFC} / \mathrm{ml})$, y no eficaz, cuando el cultivo fue positivo a cualquier germen común ( $\geq 20 \mathrm{ufc} / \mathrm{ml})$.

La selección de la muestra fue por conveniencia, por la condición y naturaleza de las variables.

En la ficha de recojo de datos se registró la hora indicada cuando se tomó la muestra antes y después del proceso de limpieza y desinfección; también se registró qué personal de Enfermería (enfermeros o técnicos) realizó el proceso de limpieza y desinfección, durante los tres meses. 
Para la colecta de la muestra, se introdujo en primer lugar agua estéril (50cc) por el canal de instrumentación, luego el cepillado del mismo y finalmente aplicación de agua estéril $(50 \mathrm{cc})$, obteniéndose un total de $100 \mathrm{cc}$ de agua como muestra para el cultivo. Estas muestras se transportaron el mismo día al laboratorio de control de calidad de la Universidad Peruana Cayetano Heredia. El aislamiento de microorganismos patógenos fue según el BAM (Manual Bacteriológico Analítico) y USP (Pharmacopeial of United States), donde se utilizaron medios de cultivo selectivos para gérmenes comunes. Las pruebas utilizadas fueron: Coagulasa para Staphylococcus aureus, oxidasa y de pigmentos para Pseudomonas aeruginosa. Para determinar la ausencia de Salmonella enterica, se utilizó medio Agar selectivo (Agar Verde Brillante, Agar Xilosa Lisina Desoxicolato, Agar con Sulfito de Bismuto, finalmente para determinar la ausencia de Escherichia coli se utilizó Medio Agar Mc Conkey.

Los resultados obtenidos fueron codificados en forma automatizada por el programa STATA 10. Se determinaron medidas de resumen (media, mediana, desviación estándar) y se utilizó para la inferencia estadística la prueba de Mc Nemar para las variables categóricas para muestras relacionadas (antes y después) y la prueba de Willcoxon para las variables numéricas.

El estudio fue aprobado por el Comité de Ética de la Universidad Peruana Cayetano Heredia.

\section{RESULTADOS}

Los procedimientos endoscópicos y sus características se pueden observar en la tabla 1.

La carga bacteriana antes del proceso de limpieza y desinfección de endoscopios fue positiva en $88 \%$ y después del proceso en $26 \%$. La carga bacteriana después del proceso de desinfección resultó positiva en $25 \%$ en las endoscopias diagnósticas $(n=44)$ y en $33 \%$ en las endoscopias terapéuticas $(n=6)(\mathrm{p}=0,6)$.

El recuento total de microorganismos antes del proceso de limpieza y desinfección fue una media de $835,3 \pm 1114,6 \mathrm{UFC} / \mathrm{ml}$, una mediana de 233 $\mathrm{UFC} / \mathrm{ml}$ y después del proceso una media de $236,3 \pm$ $700,7 \mathrm{UFC} / \mathrm{ml}$ y una mediana de $10 \mathrm{UFC} / \mathrm{ml}$ siendo esta diferencia estadísticamente significativa $(\mathrm{p}=$ 0,000001) (Gráfico 1).

Los microorganismos aislados antes y después del proceso de limpieza y desinfección de alto nivel se muestran en la tabla 2. Se encontró diferencia estadística significativa en la frecuencia de Pseudomonas aeruginosa $(\mathrm{p}=0,006)$ y Salmonella enterica $(0,00001)$.

Se aislaron dos o más gérmenes en todos los cultivos obtenidos antes y después del proceso de limpieza y desinfección de endoscopios (Tablas 3 y 4).

Tabla 1. Características del procedimiento endoscópico en Hospital de Nivel III- $2010(\mathrm{n}=50)$.

\begin{tabular}{lcc}
\hline & n & \% \\
\hline Procedimiento endoscópico & & \\
$\quad$ Diagnóstico & 44 & 88 \\
Terapéutico & 6 & 12 \\
$\quad$ Endoligadura de várices esofágicas. & 1 & \\
$\quad$ Argón Plasma. & 1 & \\
$\quad$ Dilatación esofágica. & 4 & \\
& & \\
Adulto & 48 & 96 \\
Pediátrica & 2 & 4 \\
Personal que realizó la limpieza y desinfección & & \\
$\quad$ Enfermera & 32 & 64 \\
$\quad$ Técnica de enfermería & 18 & 36 \\
\hline
\end{tabular}




\section{INVSTIGACION ORIGINAL IORIGINAL RESEARCH}

Samamé L y col.

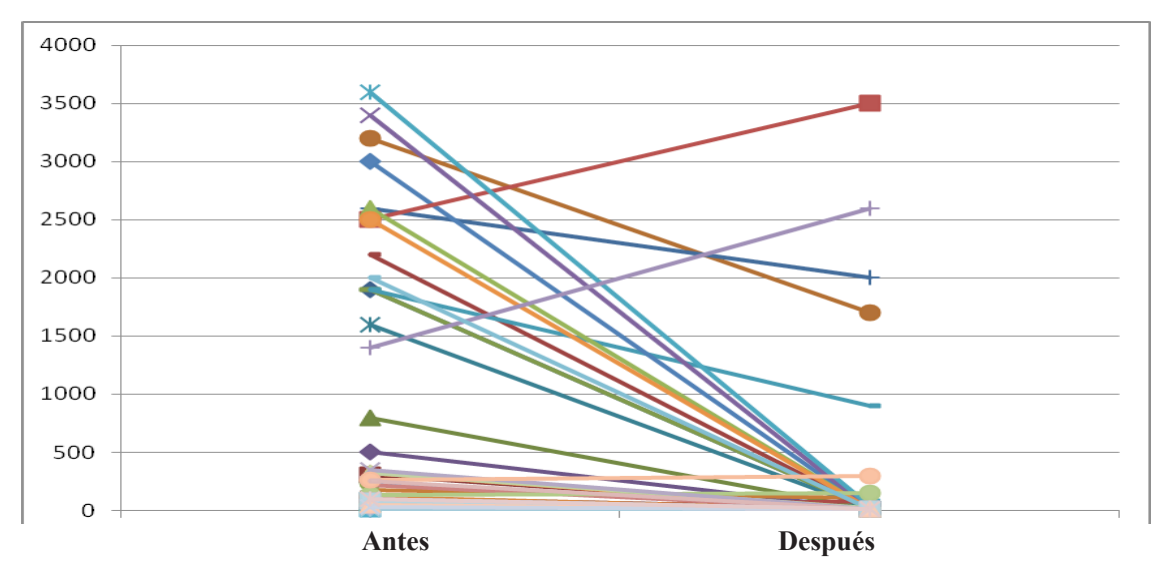

Gráfico 1. Recuento de microorganismos antes y después del proceso de limpieza y desinfección de endoscopios. Hospital de Nivel III- 2010.

Tabla 2. Microorganismos patógenos más frecuentes antes y después del proceso del proceso de limpieza y desinfección de endoscopios. Hospital de Nivel III -2010 (n=50).

\begin{tabular}{lccccr}
\hline & \multicolumn{2}{c}{ Antes } & \multicolumn{2}{c}{ Después } & \multicolumn{1}{c}{$p$} \\
\hline Staphylococcus aureus & $\mathbf{n}$ & $\mathbf{\%}$ & $\mathbf{n}$ & $\mathbf{\%}$ & \\
Pseudomonas aeruginosa. & 5 & 10 & 4 & 8 & 0,7 \\
Salmonella enterica & 25 & 50 & 11 & 22 & 0,006 \\
Escherichia coli & 42 & 84 & 11 & 22 & 0,00001 \\
\hline
\end{tabular}

Tabla 3. Aislamiento de microorganismos en las muestras obtenidas antes del proceso de limpieza y desinfección de endoscopios, Hospital de Nivel III- 2010.

\begin{tabular}{lr}
\hline Microorganismos & muestras \\
\hline Staphylococcus aureus, Pseudomonas aeruginosa & 3 \\
Staphylococcus aureus, Salmonella spp & 5 \\
Staphylococcus aureus, Escherichia coli & 1 \\
Staphylococcus aureus, Pseudomonas aeruginosa, Escherichia coli, Salmonella enterica & 1 \\
Pseudomona aeruginosa, Salmonella enterica & 25 \\
Pseudomona aeruginosa, Escherichia coli & 4 \\
Salmonella enterica, Pseudomonas aeruginosa, Escherichia coli & 4 \\
Salmonella enterica, Escherichia coli & 8 \\
\hline
\end{tabular}

Se obtuvieron 25 muestras con la presencia de Salmonella enterica y Pseudomonas aeruginosa antes del proceso de limpieza y desinfección de alto nivel y 10 muestras con la presencia de Salmonella enterica y Pseudomonas aeruginosa después del proceso. Pseudomonas aeruginosa, Salmonella enterica fueron los microorganismos aislados con más frecuencia antes y después del proceso de limpieza y desinfección de los endoscopios.
La carga bacteriana según días de activación del desinfectante de alto nivel (glutaraldehído al 2\%) después del décimo día de uso fue positivo en $55 \%$ y antes del noveno día fue $19 \%$, siendo esta diferencia estadísticamente significativa $(\mathrm{p}=0,04) \quad($ Gráfico 2$)$. Hasta el quinto día de activación del glutaraldehído al $2 \%$, el $100 \%$ de los cultivos fueron negativos. 
Tabla 4. Aislamiento de microorganismos en las muestras obtenidas después del proceso de limpieza y desinfección de endoscopios. Hospital de Nivel III- 2010.

\begin{tabular}{lr}
\hline Microorganismos & Muestras \\
\hline Staphylococcus aureus, Pseudomonas aeruginosa & 3 \\
Staphylococcus aureus, Salmonella enterica & 4 \\
Staphylococcus aureus, Escherichia coli & 1 \\
Staphylococcus aureus, Pseudomonas aeruginosa, Escherichia coli, Salmonella enterica & 0 \\
Pseudomonas aeruginosa, Escherichia coli, Salmonella enterica & 1 \\
Staphylococcus aureus, Pseudomonas aeruginosa, Salmonella enterica & 3 \\
Staphylococcus aureus, Salmonella spp, Escherichia coli & 10 \\
Pseudomona aeruginosa, Salmonella enterica & 2 \\
Salmonella enterica, Pseudomonas aeruginosa, Escherichia coli & 1 \\
\hline
\end{tabular}

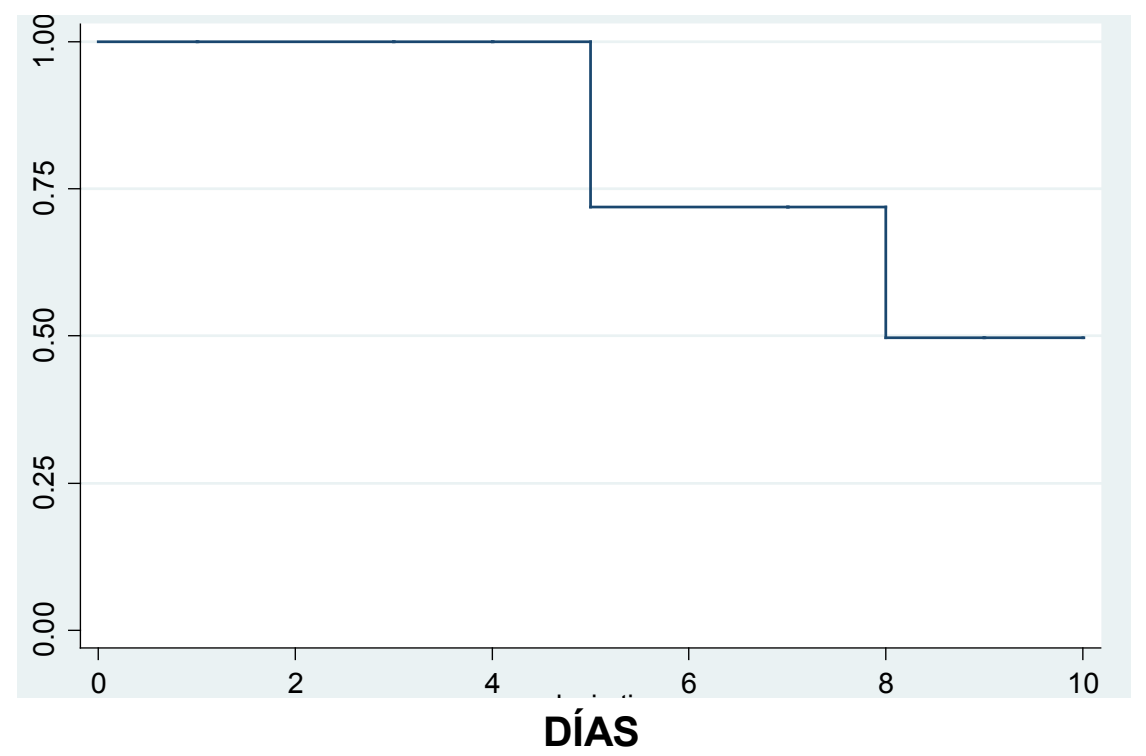

Gráfico 2. Curva de Kaplan-Mayer de la carga bacteriana según días de uso del desinfectante (Glutaraldehído al 2\%). Hospital de Nivel III-2010.

\section{DISCUSIÓN}

Los equipos endoscópicos utilizados en endoscopía digestiva para fines de diagnóstico o terapéutico en niños y adultos, deben estar en condiciones óptimas y libres de microorganismos patógenos, para evitar infecciones intrahospitalarias, frente a esta situación las Enfermeras y Técnicas de Enfermería desarrollan el proceso de limpieza y desinfección de alto nivel de los endoscopios. Actualmente la endoscopia tiende a ser más terapéutica, sin embargo durante el estudio realizado, sólo el 12\% fue terapéutica.
Se ha demostrado que los cultivos microbiológicos del endoscopio de forma periódica permiten la detección de deficiencias en el proceso de limpieza y desinfección de alto nivel $(8,9)$. El cultivo del agua estéril que se hace correr dentro de los canales del endoscopio, junto con el cepillado del mismo en forma aséptica, es un test sensible de la efectividad del reprocesamiento del endoscopio (10).

En nuestro estudio, al encontrar una carga bacteriana positiva en $26 \%$ después del proceso de limpieza y desinfección se evidenció que el proceso no fue óptimo. En Brasil (5) se encontró 48,2\%, en 
Barcelona, España 12\% (6) y en Australia 0,4\% (7). Los resultados obtenidos en este estudio difieren a los reportados por otros, probablemente por la metodología utilizada, tomándose mayor muestra y por un periodo más largo.

Al comparar el recuento total de microorganismos antes y después del proceso de limpieza y desinfección de los endoscopios se observó que se encontraban muy dispersos, encontrándose valores menores de $10 \mathrm{UFC/}$ $\mathrm{ml}$ hasta $3600 \mathrm{UFC} / \mathrm{ml}$ siendo la mediana la medida de tendencia central más representativa, existiendo una diferencia estadísticamente significativa $(p=$ $0,000001)$. Esto indica que la realización de un buen proceso de limpieza y desinfección de los endoscopios permite la eliminación de agentes patógenos.

Los gérmenes patógenos encontrados en mayor porcentaje fueron Salmonella enterica y Pseudomonas aeruginosa, coincidiendo con los reportados por otros estudios $(5,6,11)$. Además, se han descrito numerosos casos de infección por Pseudomonas aeruginosa y Salmonella enterica a través de endoscopias digestivas altas, debido al insuficiente proceso de limpieza y desinfección, relacionado con el tiempo de inmersión del endoscopio, uso de desinfectantes inadecuados y otros. (11).

Es importante resaltar la capacidad de supervivencia en superficies inertes y húmedas de la Pseudomonas aeruginosa por tiempos prolongados. Se han descrito como posibles reservorios de Pseudomonas aeruginosa a incubadoras contaminadas, equipos de terapia respiratoria y lavatorios donde además se las clasifica como multidrogorresistente (12).

Las bacterias responsables de las infecciones por vía endoscópica con mayor frecuencia son: H. pylori y Salmonella spp; pero hay otras que pueden transmitirse por esta vía como Escherichia coli, Staphylococcus epidermidis, Klebsiella spp, Serratia marcescens y Clostridium difficile. Entre los virus potencialmente transmisibles destacan el VIH, Hepatitis B, Hepatitis C. La transmisión de estas infecciones resulta de la deficiente limpieza y desinfección de los endoscopios $(2,13)$. En este trabajo no se aislaron todos los gérmenes (virus, bacterias), debido al alto costo para su aislamiento con medios de cultivo selectivo.

Por otro lado, la formación de biofilm por las bacterias contaminantes dentro de los endoscopios en los canales húmedos internos les permite ser más resistentes a la acción de los desinfectantes. Los principales microorganismos aislados en la formación de biofilm son los bacilos gram negativos como Pseudomonas aeruginosa, Escherichia coli (4).

Considerando entonces, el riesgo de adquirir un proceso infeccioso a través de los endoscopios, las guías de la American Society for Gastrointestinal Endoscopy (ASGE), la European Society Gastrointestinal Endoscopy (ESGE), establecieron recomendaciones para el reprocesamiento de los endoscopios (14). El cumplimiento de estas guías previno el $91,3 \%$ de infecciones relacionado a endoscopia digestiva alta en Estados Unidos y el 97,2\% en otros países durante 1974 y 2004 (15).

En este estudio se encontró una carga bacteriana de $55 \%$ después del décimo día de haber sido activado el desinfectante de alto nivel (glutaraldehído al $2 \%$ ), encontrándose una diferencia estadísticamente significativa. Este resultado podría suponer la presencia de biofilm, dilución por el agua de enjuague previa a la desinfección provocando una reducción en forma gradual de la efectividad del desinfectante pasado los 10 días de haber sido activado.

Dado que cada desinfectante ejerce su acción a una concentración y temperatura determinada, es recomendable comprobar al menos una vez al día mediante un indicador químico que el desinfectante se encuentra en su concentración efectiva mínima (15).

El desinfectante de alto nivel (glutaraldehído al $2 \%$ ) alcanza su máxima capacidad microbicida a ser activado, pero en esta condición es inestable, por lo que su duración es de 14 días. La actividad microbicida se ve afectada por tiempo de uso, dilución y carga de materia orgánica, por lo cual debe ser controlado (16).

En conclusión, los resultados del estudio demuestran que el proceso de limpieza y desinfección de alto nivel de los endoscopios no fue efectivo. Los patógenos más frecuentes fueron: Salmonella enterica, Pseudomonas aeruginosa y Escherichia coli. El desinfectante de alto nivel (glutaraldehído al 2\%) no es efectivo después del décimo día de haber sido activado.

Se deberían realizar trabajos de investigación institucional analíticos para determinar los factores de riesgo relacionados al proceso de limpieza y desinfección de los endoscopios en todos los centros asistenciales de la red. Se recomienda no utilizar el desinfectante de alto nivel (glutaraldehído al 2\%) pasado los 10 días de haber sido activado. 
Debemos tener presente que se debe aplicar el principio de calidad y seguridad del paciente teniendo como objetivo la atención del paciente libre de riesgos.

\section{Declaración de financiamiento y de conflictos de intereses:}

El estudio fue financiado por Luz María Samamé. Los autores declaran no tener algún tipo de conflicto de interés en la investigación realizada.

\section{Correspondencia:}

Frine Samalvides

Calle Francia 427 Dpto. 202 Urb. Balta, Lima 18.

Correo electrónico: frine.samalvides@upch.pe

\section{REFERENCIAS BIBLIOGRÁFICAS}

1. Nelson D, Muscarella L. Current issues in endoscope reprocessing and infection control during gastrointestinal endoscopy. World J Gastroenterol (Internet). 2006 (citado 10 de feb 2011). 12(25): 39533964. Disponible en: http://www.wjgnet.com/10079327/12/3953.pdf

2. Flores L, Villalobos D, Rodríguez R, Navarro D, Martínez M, Gonzales L, et al. Endoscopia digestiva superior en pediatría. Colombia Médica (Internet). 2005; 36(2):42-51. (Citado 20 de Diciembre 2010). Disponible en: http://redalyc.uaemex.mx/ pdf/283/28310011.pdf

3. Sussmann O, Martínez R. Antisépticos y desinfectantes. En: Quintero G, Nieto JA, Lerma C. Infección en cirugía. Bogotá: Médica panamericana; 2001 .p. 58-59.

4. Albornoz H, Guerra S. Manual de prevención de infecciones en procedimientos endoscópicos (Internet). Montevideo, Uruguay: Federación Médica del Interior; 2008.(Citado el 26 de Agosto 2011). Disponible en: http://www.cocemi.com.uy/ docs/endo2008.pdf

5. Machado A, Mancini A, Contijo P, Geocze S, Fischman O. Microbiologic profile of flexible endoscope disinfection in two Brazilian hospitals. Arq Gastroentero. 2006; 43(4): 255-258.

6. Medina M, Rodríguez B, Rodríguez M, et al. Nivel de desinfección de los endoscopios como indicador de calidad de una unidad de endoscopia digestiva. Gastroenterol Hepatol. 2009; 32(3): 202-203.

7. Gillespie E, Kotsanas D. Microbiological monitoring of endoscopes: 5-year review. Gastroenterol Hepatol.2008; 23(7): 1069-1074.
8. Acosta S. Controles microbiológicos de los endoscopios (Internet). Buenos Aires: Sanatorio Adventista del Plata; 2006. (Citado 10 noviembre 2010]. Disponible en: http://ebookbrowse. com /controles-microbiologicos-de-endoscopios-iipdf-d135584130

9. Beilenhoff U, Neuman CS, Rey JF, et al. Guideline for quality assurance in reprocessing: Microbiological surveillance testing in endoscopy (Internet). Manching: ESGENA; 2007. (Citado el 16 de febrero del 2011). Disponible en: http://www.esge.com/ assets/downloads/pdfs/guidelines/2007_quality_ assurance_in_reprocessing.pdf

10. Gnass S. Está seguro que su endoscopio es seguro. Ecuador: Sociedad Ecuatoriana de microbiología, XIX Congreso latinoamericano y Sexto Ecuatoriano de microbiología; 2008.

11. Beilenhoff U, Neuman CS, Rey JF, et al. And the ESGE Guideliness Committee. ESGE-ESGENA guideline: Cleaning and disinfection in gastrointestinal endoscopy. Manching: ESGENA; 2008.

12. Rivera M, Rodríguez C, Huayan G. Pseudomonas aeruginosa productora de betalactamasa clásica y de espectro extendido en reservorios de un servicio de neonatología. Rev Perú Med Exp Salud Pública. 2008; 25(2): 250-252.

13. Giuffré C. Control de las infecciones asociadas a los endoscopios. En: Efron E, Ezcurra C, Freuler C, Guelfand L, Maimone S, Soloaga R. Epidemiologia y control de infecciones en el hospital. Argentina: Editorial Ediciones de la Guadalupe; 2006.p. 417421.

14. Santolaria S, Ducons J, Bordas J. Limpieza y desinfección de endoscopia digestiva (Internet). Gastroenterol Hepatol; 2007 (Citado 15 de Mayo del 2010); 30: 25-35. Disponible en: http://www.elsevier. es/en/node/2051159

15. Heredia C. Desinfección y esterilización en procedimientos endoscópicos. Gastroenterol Latinoam. 2010; 21 (2): 319-322.

16. Gonzales A, Cruz C, Rosas. Desinfección de alto nivel (Internet). Santiago de Chile: Ministerio de Salud del gobierno de Chile; 2008. (Citado 25 de Setiembre 2011). Disponible en: http://www. ssvaldivia.cl/normas_iih/2008/01_08\%20 NORMA_01_DAN.pdf

Recibido: 12/08/2013

Aceptado: 07/10/2014 